\title{
A Técnica Esportiva em Aulas de Educação Física: um olhar sobre as tendências sócio-culturais.
}

\author{
Heitor de Andrade Rodrigues * \\ Suraya Cristina Darido **
}

\begin{abstract}
Resumo: O ensino da técnica esportiva em aulas de Educação Física é assunto bastante polêmico. É preciso destacar que nos chama a atenção o mal-entendido de que tratar o esporte de forma crítica seria o mesmo que ser contra o ensino da técnica. Diversos fatores contribuíram na configuração dessa realidade, dentre eles suspeitamos da incompreensão das propostas elaboradas no âmbito das tendências sócio-culturais. Assim, o objetivo desse trabalho foi investigar a concepção de técnica esportiva no ensino da Educação Física, no âmbito das tendências sócio-culturais. Ao longo do texto, é possível identificar novas finalidades quanto ao ensino das técnicas esportivas, como a preocupação com os interesses dos alunos que se movimentam, consideração do repertório cultural desses alunos, além de propor que as aulas não se restrinjam à realização desses movimentos, mas também incluam o conhecimento do universo social, político, econômico e cultural das manifestações esportivas.
\end{abstract}

Palavras-Chave: Ensino. Educação Física e treinamento. Características culturais.

\section{INTRODUÇÃo}

As discussões sobre o que deve ser ensinado em aulas de Educação Física escolar continuam em constante debate por parte dos docentes do Ensino Superior e Educação Básica.

Apesar dos embates, nos últimos anos parece surgir certo consenso entre as tendências sócio-culturais ${ }^{1}$ em torno dos conhecimentos

\footnotetext{
"Mestrando na área de pedagogia da motricidade humana. Departamento de Educação Física UNESP. Rio Claro, SP, Brasil. E-mail: triheitor@yahoo.com.br

" Doutora em Psicologia Escolar e do Desenvolvimento Humano. Livre Docente pelo Departamento de Educação Física UNESP Rio Claro, SP, Brasil. E-mail: surayacd@ rc.unesp.br

${ }^{1}$ Consideramos tendências sócio-culturais aquelas propostas que tentaram superar a visão biológica da Educação Física na escola, viabilizando novos olhares para a área, tais como a crítico-emanciapatório de Elenor Kunz, a cultural de Jocimar Daólio, a crítico-superador de Soares et al. e a sistêmico/fenomenológica de Mauro Betti.
} 
a serem ensinados e aprendidos pelos alunos dessa disciplina, mais especificamente conhecimentos ligados à "cultura corporal", "cultura corporal de movimento", ou "cultura de movimento".

$\mathrm{Na}$ percepção desse grupo de professores caberá ao componente curricular Educação Física tratar das diversas manifestações dessa cultura, tais como o esporte, o jogo, a dança, a ginástica, etc. $\mathrm{O}$ que existe de divergência entre esses autores são as formas de abordar essas manifestações corporais e o papel da Educação Física na escola.

De forma geral, as abordagens sócio-culturais da Educação Física nas últimas décadas vêm tecendo severas críticas na relação entre Educação Física e Esporte, alertando para o seu caráter reprodutivista e conservador.

$\mathrm{Na}$ análise de Bracht (2000), por exemplo, essas críticas em relação ao papel educativo do esporte no âmbito escolar geraram uma série de equívocos e mal entendidos, que trouxeram conseqüências à prática pedagógica dos professores.

O primeiro equívoco é o de que aqueles que criticam o esporte são contra o esporte, numa visão maniqueísta de que ou se é a favor, ou se é contra o esporte. Assim, a crítica vai no sentido de abolí-lo e negá-lo como conteúdo das aulas de Educação Física.

Outro mal-entendido é o representado pela oposição entre o rendimento e o lúdico, considerados pólos distintos e contrários, atribuindo ao rendimento todos os defeitos do esporte e ao lúdico toda a virtude. Discorre, ainda, sobre o mal-entendido de que tratar criticamente o esporte seria substituir o movimento em favor da reflexão (BRACHT, 2000).

Dentre os diversos equívocos, um nos chama a atenção e será o foco da análise desse artigo. De acordo com Bracht (2000) tratar o esporte de forma crítica significaria ser contra a técnica esportiva. Ou seja, aqueles que tratam o esporte de forma crítica negam a técnica e consideram tecnicistas os que dela fazem uso.

Ele afirma que as propostas pedagógicas elaboradas com enfoque crítico não buscaram abolir o ensino da técnica esportiva,

Movimento, Porto Alegre, v. 14, n. 02, p. 137-154, maio/agosto de 2008. 
ou seja, negarem a aprendizagem das destrezas motoras esportivas. Ao contrário, propuseram o ensino dessas técnicas dotadas de outros sentidos, objetivos e finalidades. Em suas palavras: "O que se criticou e se critica então, é a subordinação inconsciente não à técnica enquanto tal, mas à finalidade a qual determinada técnica está a serviço". (BRACHT, 2000, p. 17).

Quais foram essas novas propostas para o ensino do esporte? Elas realmente colaboraram com uma nova visão para o ensino das técnicas esportivas ou essas dúvidas ainda permanecem?

Assim, o objetivo do presente estudo é investigar a concepção de técnica esportiva no ensino da Educação Física, no âmbito das tendências sócio-culturais.

Optamos por essa temática por considerarmos, assim como Bracht (2000), persistirem diversos equívocos em relação ao ensinoaprendizagem das técnicas esportivas. Entendemos que existam muitas dúvidas entre os professores no que diz respeito ao espaço que a técnica deve ocupar quando a intenção é ensinar esportes aos alunos.

\section{ReVIsÃo de Literatura}

Um dos precursores do discurso da técnica numa visão sóciocultural foi expresso na clássica obra intitulada "Metodologia do Ensino da Educação Física" de Soares et al (1992). De acordo com os autores, o texto dessa obra trata de uma pedagogia emergente que visa responder aos interesses e anseios da classe trabalhadora, por meio da tematização da cultura corporal na perspectiva dessa classe, apontando e construindo caminhos para a transformação social.

Soares et al (1992) também realizaram pesadas críticas ao esporte e suas relações com a Educação Física, denunciaram o estado de subordinação da Educação Física aos princípios e códigos da instituição esportiva, tais como o rendimento atlético, competição, comparação de rendimentos, etc. Além disso, ressaltam que o esporte reproduz os significados da sociedade capitalista, sendo

Movimento, Porto Alegre, v. 14, n. 02, p. 139-154, maio/agosto de 2008. 
considerado uma forma de controle social, por meio da adaptação do praticante aos valores e interesses dessa sociedade.

Na proposta desse coletivo de autores, o esporte é um fenômeno social, tema da cultura corporal e merece ser ofertado na escola, mas necessita ser questionado e criticado no sentido de desmistificá-lo.

Já em relação à técnica esportiva, alertam para que o ensino do esporte não se esgote em gestos técnicos. Apesar dessa ressalva, deixam claro que esses gestos podem ser ensinados, mas que os professores não devem se restringir a esses aspectos:

Colocar um limite para o ensino dos gestos técnicos, contudo, não significa retirá-los das aulas de Educação Física na escola, pois acredita-se que, para dizer que o aluno possui "conhecimento" de determinados jogos que foram esportivizados, não é suficiente que ele domine os seus gestos técnicos (SOARES et al, 1992, p. 71).

Fica evidente nessa proposta crítico-superadora que o ensinoaprendizagem dos gestos técnicos podem ser viabilizados aos alunos, mas que a intenção central é que a prática pedagógica do professor promova a reflexão e crítica sobre aspectos econômicos, sociais, políticos e culturais dessas práticas, o que não exclui o conhecimento da cultura a respeito da técnica.

Kunz (2004) debruçou-se na análise do esporte em nossa sociedade. Em sua obra, o autor tece inúmeras críticas a essa manifestação cultural, apontando os princípios que a regem, tais como a comparação objetiva e sobrepujança, conduzindo-o a consequiências como a seleção, especialização e instrumentalização.

Para superar essa realidade, o autor propõe uma teoria pedagógica que esteja atrelada a uma didática comunicativa e que possibilite aos alunos a emancipação. Essa emancipação, para ser efetiva, passaria de um estado inicial - caracterizado pela falsa consciência e coerção auto-imposta - a um estado final - no qual se estaria livre dessa falsa consciência e das coerções auto-impostas (KUNZ, 2004). No caso específico do esporte, a falsa consciência seria considerar um esporte de alto rendimento o modelo a ser seguido por todo e

Movimento, Porto Alegre, v. 14, n. 02, p. 137-154, maio/agosto de 2008. 
qualquer praticante, e sujeitar-se às exigências físicas e técnicas desse modelo. Nesse caso, caracterizaria-se como coerção auto-imposta.

Retomando o interesse específico desse estudo, qual será a concepção de Kunz (2004) sobre a questão da técnica no processo de ensino-aprendizagem dos esportes?

Kunz (2004) esclarece que a grande evolução do esporte se deve, em parte, ao progresso científico e tecnológico, mas que esta evolução também contribuiu para o surgimento de movimentos estereotipados em sua prática.

Nesse sentido, movimento, desprovido da subjetividade de quem o realiza, é fator de alienação. O processo de ensino-aprendizagem deverá se concentrar sobre a pessoa que se movimenta e não sobre os movimentos desta, considerando os interesses, sentidos e significados que cada um atribui aos movimentos.

Ainda denuncia que no ensino dos esportes encontram-se inúmeros elementos castradores da subjetividade, já que não existem oportunidades de experiências e de movimentos próprios, mas de movimentos pré-moldados.

Apesar das inúmeras críticas do autor em relação ao esporte, demonstra não ser contra o ensino da técnica, apontado que esses movimentos podem até ser alcançados, mas não são o objetivo central ou único das aulas realizadas com o enfoque crítico-emancipatório. Segundo o autor, trata-se de repensar a forma e os momentos de priorizar a técnica no ensino da Educação Física (KUNZ; SOUZA, 2003).

Podemos inferir, a partir das idéias do autor, que a técnica pode até vir a ser realizada pelo aluno, mas o ensino do esporte nessa concepção privilegiará a construção dos movimentos a partir das vivências individuais e coletivas, que façam sentido e tenham significado ao praticante. O movimento pode não se aproximar do padrão técnico dito mais eficiente, mas viabilizar ao aluno a prática autônoma no usufruto do lazer, um agir solidário, cooperativo, participativo e, acima de tudo, o desenvolvimento de capacidades criativas e críticas.

Movimento, Porto Alegre, v. 14, n. 02, p. 139-154, maio/agosto de 2008. 
Kunz (2000), analisando o esporte a partir de uma abordagem fenomenológica, indica um ensino do esporte que atente para aspectos relativos à percepção, sensibilidade e intuição, e afirma que esses aspectos são decisivos na qualidade da execução dos diferentes movimentos. A percepção no sentido fenomenológico ligado ao esporte é determinada pelos movimentos que a pessoa realiza e, ao mesmo tempo, os movimentos realizados por ela são determinados pela percepção. Isso permite afirmar que a percepção de acerto na execução de um movimento será o critério para constituição do movimento no sentido pessoal.

Dessa forma Kunz (2000, p. 7) apresenta:

\begin{abstract}
No esporte, eu consigo um maior número de êxitos quando chutar a bola ao gol ou arremessar à cesta, não quando eu seguir apenas corretamente as indicações técnicas externas na efetivação do movimento padrão, mas quando eu começar a sentir que o movimento foi corretamente realizado. É a sensação do "acertei!" [...]. Será que os excessivos comandos externos, na chamada "correta" execução de um movimento no esporte não elimina essa consciência de valor?
\end{abstract}

Parece plausível o questionamento de Kunz (2000) em referência à função da percepção individual de acerto na constituição dos movimentos, mas a dúvida que surge é em relação aos alunos que vivenciam poucas oportunidades de acerto na execução dos movimentos. Nesse caso, qual será o papel do professor? Fornecerá informações e demonstrações de movimentos considerados por ele mais eficientes ou permitirá experiências livres de intervenção até que o aluno tenha sucesso?

Acreditamos ser a composição desses dois fatores, o aluno sente, percebe, vivencia a experiência, mas também obtém algumas informações do professor. Caso contrário, corremos o risco de nos restringirmos a um empirismo injustificado, no qual o aluno aprende apenas por tentativa e erro. Nesse caso, seria obrigar o aluno a "reinventar a roda" a cada tentativa.

Movimento, Porto Alegre, v. 14, n. 02, p. 137-154, maio/agosto de 2008. 
Daólio (2004a, 2004b), apoiando-se em autores da antropologia, trouxe contribuições importantes ao tema da técnica no campo da Educação Física.

Para desenvolver a noção de técnica corporal ele baseia-se em Mauss (1974), para o qual as técnicas corporais são maneiras como os homens, sociedade por sociedade e de maneira tradicional, sabem servir-se de seus corpos. Mauss (1974) considera os movimentos corporais como expressão de elementos de determinada sociedade. Dessa forma, não existem movimentos naturais, mas determinados pela cultura em que foram socializados, traduzindo os valores de um dado grupo.

Outro aspecto apontado por Mauss (1974) é que esses movimentos corporais, mais precisamente as técnicas corporais, são incorporados pelos membros da sociedade por meio do que ele chama de imitação prestigiosa. A criança ou adulto imita os gestos que foram realizados por pessoas de prestígio ou que eles confiam, e que, de certa forma, alcançaram êxito na execução.

Trazendo a discussão para o âmbito da Educação Física, Daólio (2004b) afirma que tradicionalmente a compreensão de técnica esteve atrelada à dimensão eficiente dos movimentos, reconhecidos como aqueles precisos e corretos. Assim, movimentos que não se aproximam desses modelos deveriam ser alvo de intervenções no sentido de aperfeiçoamento. Para o autor, privilegiando a dimensão eficiente dos movimentos, a Educação Física deixou de lado aspectos simbólicos, perdendo, assim, a oportunidade de considerar o corpo capaz de produzir e expressar uma dinâmica cultural. Ainda para Daólio (2004b), a grande maioria dos estudos na Educação Física dá um tratamento instrumental à técnica. Coletam alguns movimentos considerados eficientes para determinada modalidade esportiva e os organiza em forma de estágios para que sejam aprendidos.

Voltemos a Mauss (1974), para o qual os membros de uma sociedade incorporam as técnicas corporais dos indivíduos dotados de prestígio ou que alcançaram êxito na execução dos movimentos.

Movimento, Porto Alegre, v. 14, n. 02, p. 139-154, maio/agosto de 2008. 
Pensando no esporte, qual é o modelo dotado de prestígio imitado e incorporado pelos alunos? Com certeza, na maioria dos casos, são os movimentos dos atletas de alto rendimento. Já foi observado inúmeras vezes os alunos quebrando os aros das tabelas de basquetebol das escolas, quando tentam de todas as formas "enterrar", copiando o modelo de alto rendimento observado na mídia. Talvez o maior problema tenha sido a Educação Física na escola adotar incondicionalmente não só os movimentos e as técnicas esportivas, mas também os seus códigos, significados e objetivos do modelo de esporte de rendimento, como a exclusão e seleção.

Em passagem reveladora em relação ao ensino das técnicas, Daólio (2004a) dá pistas de que, em determinadas circunstâncias, seria possível o ensino de alguns gestos técnicos, mas não identifica quais seriam esses momentos: [...] não existe técnica melhor ou mais correta, senão em virtude de objetivos claramente explicitados e em relação aos quais possa haver consenso entre professor e alunos (DAÓLIO, 2004a, p. 95).

Discutindo a pedagogia dos esportes coletivos, Daólio (2002) afirma que, na perspectiva tradicional, a técnica esportiva sempre esteve no centro das atenções. Nesse modo de compreender o esporte, bastante difundido no país, acredita-se que o aluno pode jogar bem o voleibol quando executa corretamente os fundamentos esportivos (manchete, toque e cortada). Na nova concepção, o autor, apoiado em Claude Bayer, aponta que a dimensão técnica não garante o acesso a um jogar inteligente, uma vez que jogar bem implica compreender a lógica estrutural do Esporte Coletivo. Aliás, considera que as modalidades esportivas coletivas podem ser agrupadas em uma única categoria por possuírem características comuns.

Nesse texto, o autor incorpora mais uma razão para minimizarmos o papel das técnicas esportivas nas aulas de Educação Física na escola, da qual compartilhamos, pois nessa concepção o que importa é a compreensão da dinâmica envolvida no jogo.

Quando refere-se especificamente ao gesto técnico dos atletas de alto nível, refere-se a sua plástica e eficiência. No entanto, lembra que essa técnica não pode ser ensinada imediatamente a todos os

Movimento, Porto Alegre, v. 14, n. 02, p. 137-154, maio/agosto de 2008. 
alunos por duas razões principais: primeiramente, por que a aprendizagem desses gestos exige grande tempo de treinamento e, em segundo lugar, por que os alunos, culturalmente situados, podem possuir outros interesses de movimentos.

Ao final do texto, Daólio (2002) defende o modelo pendular em que a técnica seja ensinada posteriormente à compreensão do jogo. Depois, faz uma ressalva importante lembrando que, para Mauss, qualquer gesto constitui-se numa técnica corporal por possuir uma tradução e significados dentro de grupos específicos. Assim, para o autor, no início da aprendizagem um aluno pode arremessar a bola à cesta com as duas mãos, ou receber a bola com um soco no voleibol, de modo que os alunos estejam usando ações inteligentes com os meios técnicos que dispõe naquele contexto cultural específico.

Concordamos com a idéia do autor de que a compreensão dos aspectos táticos - o por que fazer - deve preceder os ensinamentos fragmentados dos gestos técnicos. Reconhecendo, assim, a importância de iniciar os alunos numa determinada modalidade pela compreensão dos objetivos e da dinâmica do jogo propriamente dito.

Todavia, parece-nos que a dúvida persiste, ou seja, qual é o momento após a compreensão do jogo de indicar aos alunos as possibilidades dos gestos técnicos? Para usar o exemplo do autor, até qual momento da aprendizagem o aluno deve/pode continuar a arremessar a bola com as duas mãos ou receber a bola de voleibol com o soco, sem que o professor apresente as técnicas mais eficientes construídas ao longo da história?

Parece não haver resposta fechada, até por que cada contexto tem características muito particulares e alunos com experiências anteriores bastante diversas.

Defendemos que as informações sobre os gestos técnicos sejam realmente oferecidas após a compreensão do jogo, desde que façam sentido para o aluno. Do mesmo modo, que não haja cobrança exacerbada aos que não conseguirem executar os movimentos no padrão correto. É preciso esclarecer também que, como afirmou Daólio (2002), na escola, o aluno terá poucas oportunidades de praticar repetidamente um gesto técnico. $\mathrm{O}$ que se espera é que ele tenha

Movimento, Porto Alegre, v. 14, n. 02, p. 139-154, maio/agosto de 2008. 
oportunidade de conhecê-lo, mesmo por que se mantiver o arremesso com as duas mãos, isso não deverá impedí-lo de atingir os objetivos de conhecer, praticar e apreciar o esporte.

Ainda assim, podemos nos questionar: o que significa oferecer as técnicas esportivas posteriormente à compreensão do jogo propriamente dito?

Lembramos um episódio que ocorreu há muito tempo quando ensinávamos natação (portanto fora do exemplo dos esportes coletivos apontados pelo autor). Seguindo as recomendações pedagógicas, oferecíamos atividades que envolviam experiências diversificadas na água numa dimensão bastante lúdica, sem preocupação com a execução e os gestos técnicos dos quatro nados.

A surpresa ocorreu quando uma garota de sete anos chegou à borda da piscina e nos questionou: "agora eu quero saber como é que eu faço com a mão? Como ela deve entrar na água?" Em outras palavras, o que a aluna estava nos questionando, aos sete anos, era justamente a técnica do nado. Ou seja, naquele exemplo, nos faltou a percepção de que havia chegado o momento de apresentar a técnica do nado crawl.

Em síntese, Daólio (2002; 2004a; 2004b) concebe a técnica como todo e qualquer gesto corporal e que cada cultura imprime nos corpos de seus membros uma série de valores que os identificam. A contribuição vem no sentido de que a Educação Física leve em consideração os aspectos culturais de sua prática, reconhecendo o repertório corporal com o qual cada aluno chega à escola, e não apenas valorizar as características biológicas. Além disso, é possível depreender de suas análises que nenhuma técnica é melhor do que outra, assim, poderá haver espaço, também, para o que denominamos de técnica esportiva, que não deixa de ser um tipo de técnica corporal. Contudo, apesar de reconhecer a necessidade da aprendizagem da dimensão técnica dos esportes coletivos, acredita que esses movimentos devam ser introduzidos em um segundo momento, após a compreensão inteligente do jogo obtida a partir do conhecimento e da vivência dos princípios operacionais e regras de ação dos esportes.

Movimento, Porto Alegre, v. 14, n. 02, p. 137-154, maio/agosto de 2008. 
Mauro Betti (1994; 1999) é mais um representante das tendências sócio-culturais na Educação Física. Em suas obras, não discute especificamente o tema da técnica esportiva, mas a partir de suas reflexões é possível inferirmos algumas idéias relevantes, que nos permitem iluminar o campo das técnicas esportivas na Educação Física escolar.

Tratando da dimensão axiológica e teleológica da Educação Física, Betti (1994) afirma que ela deve ser capaz de oferecer aos alunos motivos geradores de sentido, com finalidade de integrá-los à esfera da cultura corporal de movimento, ou seja, levar os alunos a descobrirem os motivos para praticar uma atividade física. Aponta, ainda, que uma ação pedagógica com esses objetivos estará impregnada do sentir e do relacionar-se, mas que a dimensão do conhecer, viabilizada por meio da linguagem, será essencial para o aluno atribuir valores às manifestações da cultura corporal de movimento.

Em estudo relativo à Educação Física e à formação para cidadania, Betti (1999) elenca alguns princípios importantes à sua consolidação, dentre eles o da formação plena, em que as dimensões humanas estejam integradas. Em trecho de sua reflexão é possível obter algumas informações sobre como entende a técnica esportiva:

\begin{abstract}
Se falamos em aprendizagem de esportes, é a mesma coisa. Se o professor quer ensinar basquetebol, é preciso ensinar as habilidades específicas da modalidade, mas que precisam estar integradas às dimensões afetiva (é preciso aprender a gostar do basquetebol), cognitiva (por exemplo, compreender as regras como algo que torna o jogo possível, a organização e as possibilidades de acesso ao esporte em nosso meio) e social (aprender a organizar-se em grupo para jogar o basquetebol) (BETTI, 1999, p. 87).
\end{abstract}

Não há, em Betti (1994; 1999), a preocupação explícita em discorrer sobre o ensino da técnica esportiva. Existe, em seus trabalhos, críticas a como essa manifestação foi desenvolvida no contexto brasileiro das décadas de 50, 60 e 70, e algumas propostas na direção de um ensino do esporte que não se restrinja apenas à prática das habilidades específicas das modalidades, mas reconhece que a

Movimento, Porto Alegre, v. 14, n. 02, p. 139-154, maio/agosto de 2008. 
aprendizagem desses movimentos é uma das dimensões necessárias à formação integral, levando em conta dimensões afetivas, cognitivas e sociais.

Mais recentemente, em importante reflexão ao lado de outros autores, Betti et al (2007) apontam algumas implicações da fenomenologia para a didática da Educação Física. Os autores afirmam que a Educação Física precisa levar os alunos a vivenciarem no esporte o gesto originário, o que eles chamam de gesto movimentante, ou seja, uma primeira experiência com o esporte que não esteja marcada por movimentos predeterminados, movimentos que permitam conhecer o esporte pelo "se movimentar" originário e não pela imitação de padrões de movimentos fixados. Apesar disso, reconhecem que nenhum movimento é totalmente inédito, pode sê-lo ao iniciante no campo da percepção, mas não o é no campo da cultura. Exempli-ficando, afirma que, quando um jogador joga futebol, está necessariamente invocando os gestos de todos aqueles que um dia praticaram esse esporte. Podemos inferir a partir dessas considerações que muitas técnicas esportivas, mesmo não tendo sido experimentadas corporalmente por nossos alunos, de alguma forma são "conhecidas culturalmente", pelo menos no campo do imaginário os alunos tomam contato com as técnicas esportivas previamente ao ambiente escolar.

Retomando as idéias de Kunz (2000/1; 2004) e Daólio (2002; 2004a; 2004b) é possível identificar um interesse em comum em romper com o ensino-aprendizagem dos esportes baseado na dimensão eficiente dos movimentos, propondo uma atenção maior ao sujeito que se movimenta e com os aspectos ligados a sua cultura, levando em conta seus interesses e desejos no movimentar-se, além de haver a necessidade de dimensionar o melhor momento para se introduzir a técnica, certamente após os alunos terem alguma compreensão dos objetivos e da dinâmica dos jogos coletivos.

Já em relação a Soares et al (1992) e Betti (1994; 1999) existe a preocupação de que o processo de ensino-aprendizagem dessas práticas não se restrinja apenas à realização dos movimentos, ao saber fazer, mas que a prática pedagógica em Educação Física esteja

Movimento, Porto Alegre, v. 14, n. 02, p. 137-154, maio/agosto de 2008. 
preocupada também com a dimensão do conhecer e, mais especificamente, conhecer o universo social, político, econômico e cultural que permeiam as manifestações esportivas.

\section{Considerações Finais}

Ao longo do texto, buscamos investigar a concepção de técnica esportiva no ensino da Educação Física, no âmbito das tendências sócio-culturais.

Existe, entre os autores, o interesse de apresentar outras finalidades ao ensino-aprendizagem das técnicas, para além daquelas adotadas no modelo tradicional de esporte. O que se propõe é que os gestos técnicos sejam um meio privilegiado para alcançar outras finalidades educativas e não a única aprendizagem necessária.

As técnicas devem ser compreendidas como um patrimônio a ser transmitido aos alunos, pois são movimentos construídos historicamente, são produtos de uma dinâmica cultural que podem ser preservados. É preciso reconhecer que a técnica, enquanto um dos elementos da cultura corporal de movimento, poderá possibilitar aos praticantes a prática autônoma do lazer e a crítica do espetáculo esportivo, desde que assuma o papel de meio e não de fim em si mesmo.

Do mesmo modo, Pires e Neves (2005) ressaltam que é fundamental conhecer as técnicas esportivas para usufruir prazerosamente do esporte e/ ou do seu consumo como espectador esclarecido. Como se vê, não trata-se de negar o espaço da técnica, mas sim de repensar o seu espaço e tempo.

As severas críticas realizadas ao Esporte e sua relação com a Educação Física conduziram a inúmeros mal-entendidos, dentre eles o de que o ensino crítico do esporte deveria preceder o ensino das técnicas.

Analisando algumas obras de tendências sócio-culturais, percebe-se que a intenção não é abolir o ensino das técnicas esportivas nos esportes.

Movimento, Porto Alegre, v. 14, n. 02, p. 139-154, maio/agosto de 2008. 
O que se propõe é um novo olhar ao ensino-aprendizagem desses movimentos, trata-se de considerar o contexto específico em que os alunos estão inseridos, bem como seus interesses e desejos no "se movimentar". Preocupam-se, também, em evidenciar que as aulas incluam de forma explícita o conhecimento sobre o esporte e não se restrinjam à prática exclusiva dos movimentos. Mesmo assim, quando houver o interesse em ensinar as técnicas esportivas das modalidades coletivas, alertam que essas aprendizagens devem acontecer após a compreensão da dinâmica do jogo.

Válido destacar, ainda, que os gestos técnicos não devem ser condição necessária e indispensável para que o aluno vivencie e pratique o esporte, ou seja, um fator que limite e exclua uma parcela dos alunos de participarem das aulas, diferente disso, propõe-se que cada aluno se aproprie, reproduza e transforme os esportes de acordo com as suas possibilidades, sejam materiais ou relativas ao repertório de movimento. Essa premissa não exclui a possibilidade do professor de apresentar aos alunos os gestos técnicos, isso porque a escolha de adotar ou descartar esses movimentos será decisão do aluno frente suas aspirações e necessidades.

No que diz respeito ao ensino do esporte na escola, o espaço/ tempo da Educação Física escolar será privilegiado para uma primeira aproximação com as técnicas esportivas, ambiente em que os alunos tenham o contato inicial com esses movimentos. Por outro lado, levando em conta os diversos objetivos a serem alcançados, parece não ser o espaço/tempo adequado para o treinamento exclusivo, prolongado e intenso das técnicas específicas dos esportes. Talvez esse papel seja delegado às escolas de esporte, nas quais o aluno opta pelo esporte que deseja realizar o aprofundamento técnico, além de desfrutar de longos períodos de prática, um dos aspectos fundamentais para apropriarem-se desses movimentos.

Também é preciso ressaltar que a aprendizagem da técnica pelos alunos não é antagônica ao prazer e ao lúdico nas aulas. Podem, dependendo do tipo de intervenção pedagógica do professor, ser aspectos simultâneos e complementares. Por isso, a importância da capacidade do professor de identificar os momentos e os modos de

Movimento, Porto Alegre, v. 14, n. 02, p. 137-154, maio/agosto de 2008. 
ensinar as técnicas esportivas. Ou, dito de outro modo por Caparroz e Bracht (2007), é necessário que os professores de Educação Física sejam autônomos em relação a sua prática pedagógica, que busquem construir e reconstruir sua competência para que não se tornem reféns de manuais elaborados por outros pesquisadores e/ou professores do âmbito universitário. Adiciona-se ao fato de que os professores atuam em ambientes de alta complexidade, incerteza, instabilidade, caráter único e dotado de conflitos de valores, em que o ensino da técnica é apenas um dos elementos que compõe essa trama.

Nesse sentido, as dúvidas e práticas dos professores não devem mais percorrer o sentido de técnicas sim ou técnicas não, mas o sentido de repensar o lugar ocupado por esses movimentos quando ensinamos esporte, com vistas à formação crítica dos alunos.

Movimento, Porto Alegre, v. 14, n. 02, p. 139-154, maio/agosto de 2008. 
Sport techniques in physical education school: a look at the socio-cultural trends.

Abstract: Teaching sports techniques lessons of

Physical Education is a very controversial subject. We must emphasize the fact that called our attention, that dealing with sport in a critical way would be the same as being against the teaching of the art. Several factors contributed in shaping this reality, among them we suspect that the proposal's incomprehension made within the socio-cultural trends. Thus, the aim of this work was to investigate the technical aspects of sports in teaching of Physical Education, as socio-cultural trends part. Throughout the text it is possible to identify new goals considering sportive techniques such as the concern with interests of students who movement, consideration of cultural repertoire of these students, in addition to proposing that the lessons do not restrict implementation of these movements, but also includes the knowledge of social, political, economic and cultural universe of sports events.

Keywords: Teaching. Physical Education and training. Cultural Characteristics.

La técnica deportiva en clases de educación física: una mirada sobre las tendencias socioculturales.

Resumen: La enseñanza de la técnica deportiva en clases de Educación Física es un asunto polémico. Es necesario destacar que nos llama la atención el mal-entendido de que tratar el deporte de forma crítica seria el mismo que ser contrario a la enseñanza de la técnica. Diversos factores contribuyeran en la configuración de esta realidad, dentro ellos sospechamos de la incomprensión de las propuestas elaboradas en el ámbito de las tendencias socio-culturales. Siendo así, el objetivo de este trabajo fue investigar la concepción de la técnica deportiva de la enseñanza de la Educación Física, en el ámbito de las tendencias socio-culturales. Al transcurrir del texto es posible identificar nuevas finalidades cuanto a la enseñanza de las técnicas deportivas como, la preocupación con los intereses de los alumnos que se movimentan, consideración del repertorio cultural de estos alumnos, a parte de proponer que las clases no se restrinjan a la realización de estos movimientos, pero también incluyan el conocimiento del universo social, político, económico y cultural de las manifestaciones deportivas. Palabras-clave: Enseñanza. Educación y entrenamiento físico. Características culturales.

Movimento, Porto Alegre, v. 14, n. 02, p. 137-154, maio/agosto de 2008. 


\section{REFERÊNCIAS}

BARROS, A. M. A prática pedagógica dos professores de Educação Física e o tratamento da dimensão conceitual dos conteúdos. 2006. 71 f. Dissertação (Mestrado em Ciências da Motricidade). - Instituto de Biociências, Universidade Estadual Paulista - Campus Rio Claro, Rio Claro, 2006.

BETTI, M. Valores e finalidades na Educação Física escolar: concepção sistêmica. Revista Brasileira de Ciências do Esporte, Campinas, v. 16, n. 1, p. 14-21, 1994.

BETTI, M. Educação física, esporte e cidadania. Revista Brasileira de Ciências do Esporte, Campinas, v. 20, n. 2 e 3, p. 84-91, 1999.

BETTI, M; KUNZ, E; ARAÚJO, L. C. G; SILVA, E. G. Por uma didática da possibilidade: implicações da fenomenologia de Merleau Ponty para a Educação Física. Revista Brasileira de Ciência do Esporte, Campinas, v. 28, n. 2, p. 39-53, 2007.

BRACHT, V. Esporte na escola e esporte de rendimento. Movimento, Porto Alegre, v. 1, n. 12, p. 14-24, 2000.

BRASIL, Ministério da Educação e Desporto. Secretaria de Ensino Médio e Tecnológico. Parâmetros Curriculares Nacionais - PCN. Brasília: MEC, SEMTEC, 2002. p. 139-179: Área: Linguagens, Códigos e suas Tecnologias - Educação Física.

CAPARROZ, F. E; BRACHT, V. O tempo e o lugar de uma didática da Educação Física. Revista Brasileira de Ciência do Esporte, Campinas, v. 28, n. 2, p. 21-37, 2007.

DAÓLIO, J. Jogos esportivos coletivos: dos princípios operacionais aos gestos técnicos - modelo pendular a partir das idéias de Claude Bayer. Revista Brasileira de Ciência e Movimento, Brasília, v. 10, n. 4, p. 99-104, 2002.

DAÓLIO, J. Da cultura do corpo. 8.ed. Campinas: Autores Associados, 2004a.

DAÓLIO, J. Educação física e conceito de cultura. Campinas: Autores Associados, 2004b.

KUNZ, E; SOUZA, M de. Atletismo. In: KUNZ, E. (Org). Didática da educação física 1. 3.ed. Ijuí: Unijuí, 2003. p. 19-54

KUNZ, E. Transformações didático-pedagógicas do esporte. 6.ed. ljuí: Unijuí, 2004.

KUNZ, E. Esporte: uma abordagem com a fenomenologia, Movimento, Porto Alegre, v. 1, n. 12, p. 1-3, 2000.

MAUSS, M. Sociologia e antropologia. São Paulo: EPU/EDUSP, 1974. v. 2.

PIRES, G. D. L; NEVES, A das. O trato com o conhecimento esporte na formação em educação física: possibilidades para sua transformação didático-metodológica. In: KUNZ, E. (Org). Didática da educação física 2. 3.ed. Ijuí: Unijuí, 2005. p. 53- 95.

Movimento, Porto Alegre, v. 14, n. 02, p. 139-154, maio/agosto de 2008. 


\section{Ensaios}

Heitor de Andrade Rodrigues, et al.

SOARES, Carmen et al. Metodologia do ensino da Educação Física. São Paulo: Cortez, 1992.

Recebido em: 06/11/2007

Aprovado em: 30/01/2008

Movimento, Porto Alegre, v. 14, n. 02, p. 137-154, maio/agosto de 2008. 